\title{
Layer-by-Layer Integration of Zirconium Metal-Organic Frameworks onto Activated Carbon Spheres and Fabrics with Model Nerve Agent Detoxification Properties
}

\author{
Rodrigo Gil-San-Millan, Pedro Delgado, Elena Lopez-Maya, Javier D. Martin-Romera, Elisa Barea, \\ and Jorge A. R. Navarro*
}

Cite This: ACS Appl. Mater. Interfaces 2021, 13, 50491-50496

Read Online

ABSTRACT: We report the controlled synthesis of thin films of prototypical zirconium metal-organic frameworks $\left[\mathrm{Zr}_{6} \mathrm{O}_{4}(\mathrm{OH})_{4}(\text { benzene-1,4-dicarboxylate-2-X })_{6}\right](\mathrm{X}=\mathrm{H}$, UiO-66 and $\mathrm{X}=\mathrm{NH}_{2}, \mathrm{UiO}-66-\mathrm{NH}_{2}$ ) over the external surface of shaped carbonized substrates (spheres and textile fabrics) using a layer-by-layer method. The resulting composite materials contain metal-organic framework (MOF) crystals homogeneously distributed over the external surface of the porous shaped bodies, which are able to capture an organophosphate nerve agent simulant (diisopropylfluorophosphate, DIFP) in competition with moisture (very fast) and hydrolyze the $\mathrm{P}-\mathrm{F}$ bond (slow). This behavior confers the composite material self-cleaning properties, which are useful for blocking secondary emission problems of classical protective equipment based on activated carbon.

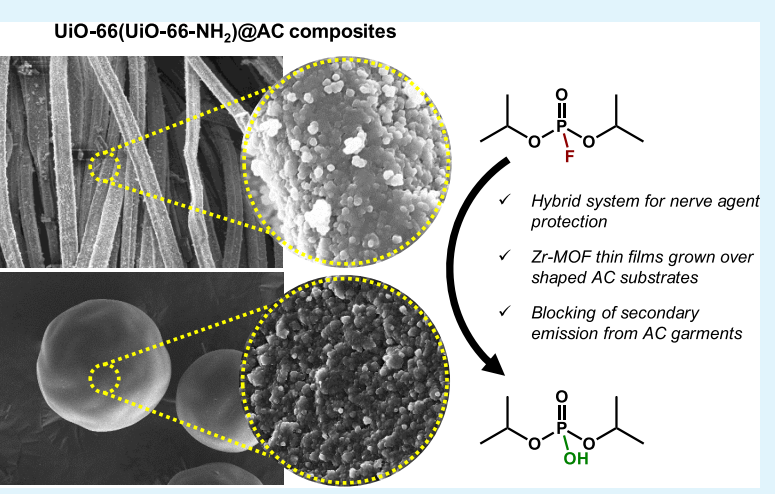

KEYWORDS: composite, thin film, chemical warfare agent, filter, protective garments, heterogeneous catalysis

\section{INTRODUCTION}

Despite the international prohibition of the use and stockpiling of chemical warfare agents (CWAs), there is a high threat of exposure to highly toxic chemicals, as a consequence of destabilizing group actions. This problem has increased the demand for CWA detection and protective equipment. ${ }^{1}$ CWA toxicity is related to lipophilicity and the reactive nature of $\mathrm{X}-$ $\mathrm{Y}$ bonds $(\mathrm{X}=\mathrm{C}, \mathrm{P} ; \mathrm{Y}=\mathrm{F}, \mathrm{Cl}, \mathrm{N}, \mathrm{S})$ typically found in the structure of these systems. These features lead to facile permeation through biological tissues and irreversibly binding to highly relevant biomolecules, namely, deoxyribonucleic acid (DNA) and acetylcholinesterase (AChE) for vesicant and nerve agents, respectively (Scheme 1$)^{2,3}$ The ideal protective systems should be able to efficiently capture and decompose these extremely toxic chemicals before they come into contact with their biological target.

Current protective systems against CWAs take advantage of high porosity, hydrophobicity and easy shaping of activated carbon (AC) adsorbents. ${ }^{4,5}$ However, AC-based protective systems lack safety, as a small fraction of the adsorbed contaminant molecule can desorb from the pore surface (a phenomenon called secondary emission) and subsequently contaminate the user. In this regard, a variety of porous metalorganic frameworks (MOFs), constructed from metal clusters connected by multitopic organic ligands, ${ }^{6}$ behave as efficient catalysts for decontamination of nerve agents. ${ }^{7-10}$ However, as
MOF materials are usually obtained in a powder form, they need to be shaped ${ }^{11}$ to allow their integration onto protective systems like suits, cartridge filters, or ventilation equipment. Recent efforts have been focused on the development of advanced protective materials based on catalytically active MOFs integrated onto textile fabrics ${ }^{12-17}$ combining the lightness and air permeation of the fibers. Still, it will be advantageous that the MOF support would have complementary adsorptive properties to increase the filter protection ability. In this regard, AC materials possess a broad range of pore sizes and are easily shaped in the form of spheres and textile fabrics suitable as filters. Nevertheless, MOF integration onto AC materials has been poorly explored. ${ }^{18-21}$

Herein, we report the controlled synthesis of two prototypical zirconium-based MOFs $\left[\mathrm{Zr}_{6} \mathrm{O}_{4}(\mathrm{OH})_{4}\right.$ (benzene1,4-dicarboxylate-2-X $\left.)_{6}\right]\left(\mathrm{X}=\mathrm{H}, \mathrm{UiO}-66 ; \mathrm{X}=\mathrm{NH}_{2}, \mathrm{UiO}-66\right.$ $\mathrm{NH}_{2}$ ) over the surface of activated carbon substrates in the form of fabrics (suited for the fabrication of protective suits) and spheres (suited as fillers on mask cartridges). We show

Received: June 28, 2021

Accepted: September 29, 2021

Published: October 13, 2021 
Scheme 1. Toxicity Mechanism of Sarin (Nerve Agent) and Sulfur Mustard (Vesicant Agent)

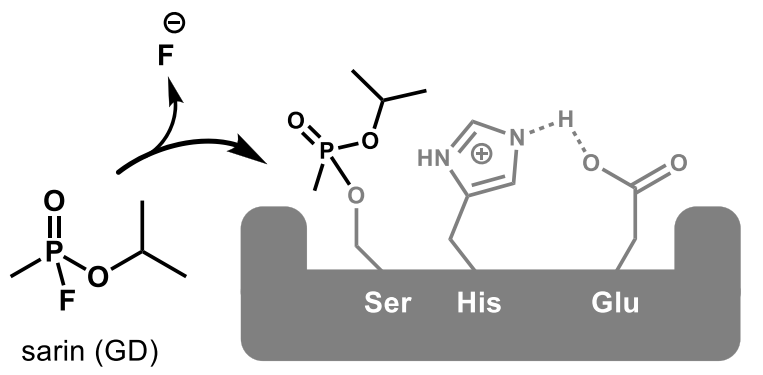

inhibited AChE enzyme

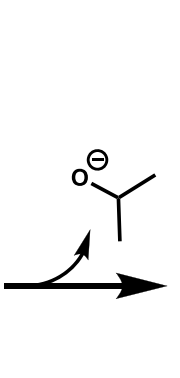

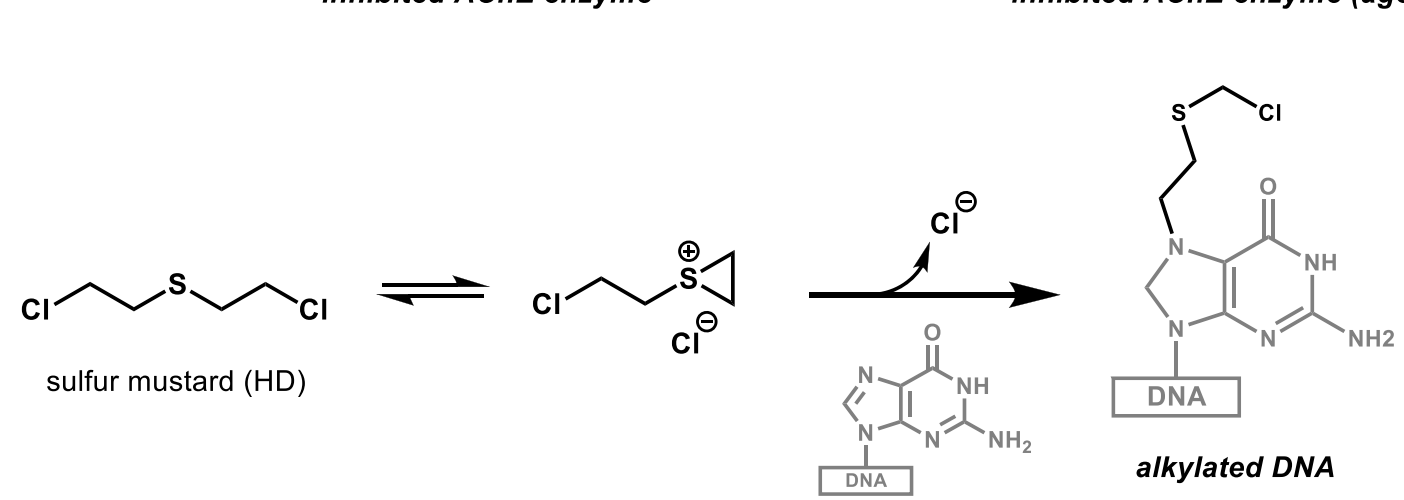

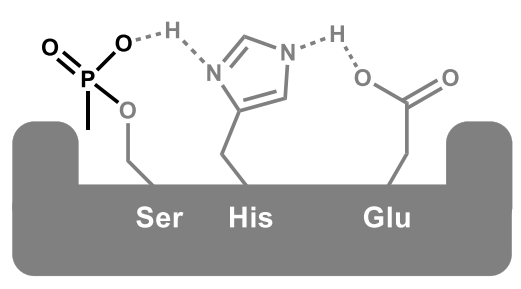

inhibited AChE enzyme (aged)

Scheme 2. Synthesis of UiO-66(UiO-66- $\left.\mathrm{NH}_{2}\right) @ A C$ (Fabrics, Spheres) Composites in a Layer-by-Layer Approach

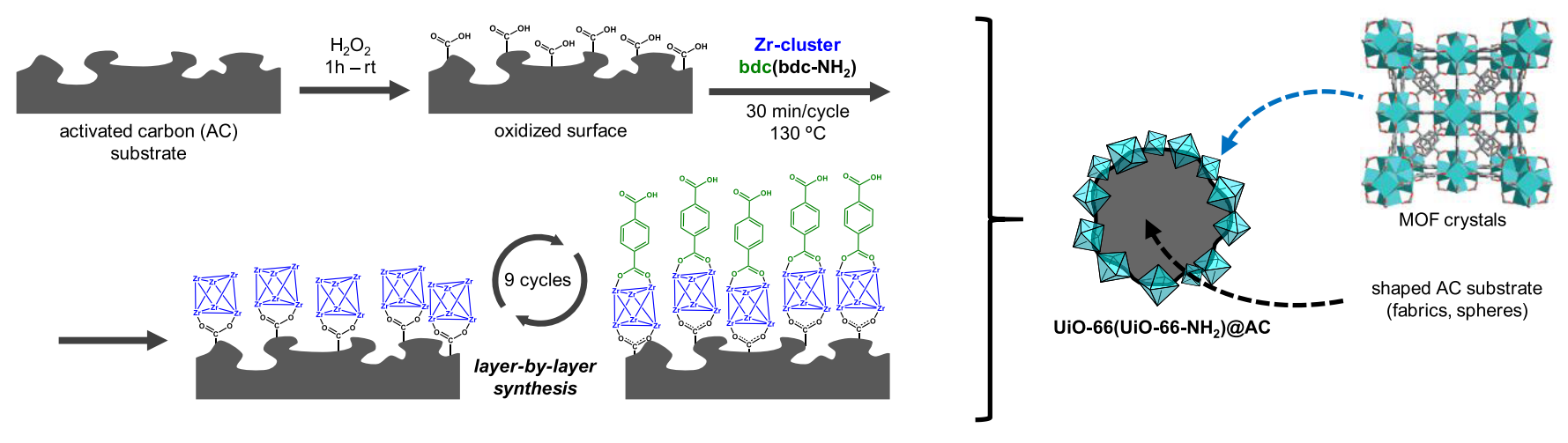

that a layer-by-layer (LBL) synthesis is more advantageous than the in situ MOF synthesis with the LBL yielding systems containing Zr-MOF thin films homogeneously dispersed over the AC shaped bodies. Moreover, the resulting MOF@AC composites behave as self-cleaning materials in the capture and degradation of the organophosphate nerve agent simulant diisopropyl fluorophosphate (DIFP) blocking the secondary emission problems of traditional AC-based protective filters.

\section{RESULTS AND DISCUSSION}

Scheme 2 shows a general synthetic procedure for the layer-bylayer (LBL) MOF thin-film growth over the shaped carbonized substrates. In the first step, the carbonized substrate, in the form of fabrics and spheres, was treated with an oxidant to increase the concentration of oxygen groups (i.e., hydroxyl, carboxylate) on its surface to provide suitable metal-ionanchoring sites. Temptative studies with nitric acid $\left(\mathrm{HNO}_{3}\right)$ and hydrogen peroxide $\left(\mathrm{H}_{2} \mathrm{O}_{2}\right)$ lead to the selection of the latter as it does not damage the AC porosity, as proven by $\mathrm{N}_{2}$ adsorption measurements (see below). This oxidative treatment led to an increase in oxygen groups on the surface as confirmed by X-ray photoelectron spectroscopy (XPS) analysis (see the Supporting Information, SI).

In the second step, two separate solutions containing the MOF precursors were prepared: (a) a preformed $\mathrm{Zr}_{6}$ oxocluster $\left[\mathrm{Zr}_{6} \mathrm{O}_{4}(\mathrm{OH})_{4}(\mathrm{AcO})_{12}\right]$ solution in dimethylformamide (DMF) $/ \mathrm{AcOH}^{22}$ and (b) a DMF solution of the organic spacer (4-benzenedicarboxylic acid $\left(\mathrm{H}_{2} \mathrm{bdc}\right)$ or amino-1,4benzenedicarboxylic acid $\left(\mathrm{H}_{2}\right.$ bdc- $\left.\mathrm{NH}_{2}\right)$ ) (see the $\mathrm{SI}$ ). The LBL crystallization process consisted of the alternate immersion of the AC substrate in the zirconium cluster and linker solutions (Scheme 2). A washing step with DMF was carried out between transfers of the AC material into the different solutions to remove any unreacted MOF precursor, thus avoiding MOF crystallization outside of the carbon shaped bodies. In this manner, strongly attached Zr-MOF films were constructed for all materials. The resulting composites were labeled UiO-66@AC(fabrics, spheres) and UiO-66$\mathrm{NH}_{2} @ A C$ (fabrics, spheres).

The MOF thin-film growth process was carried out using $1 \mathrm{~h}$ immersion at $130{ }^{\circ} \mathrm{C}$ in each component solution. A combined study of powder X-ray diffraction (PXRD), inductively coupled 
plasma-mass spectrometry (ICP-MS) (Figure 1a-d), and thermogravimetric analysis (TGA) (Figures S7 and S8) over
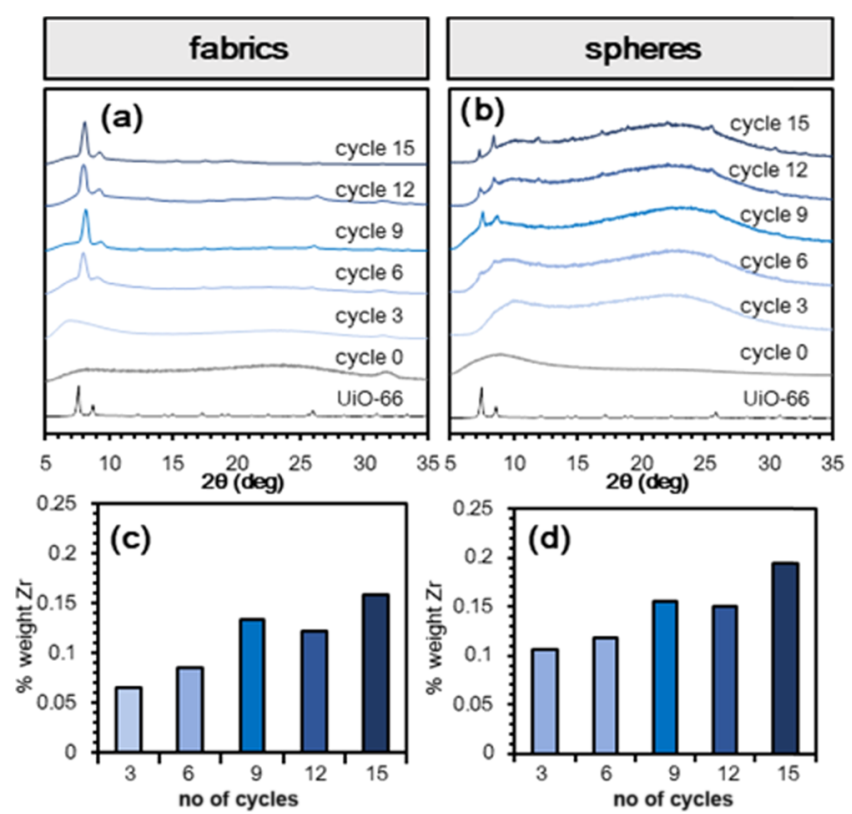

Figure 1. Study of UiO-66 growth over shaped activated carbon (AC) substrates. PXRD patterns for UiO-66@AC composite materials after different number of cycles for (a) fabrics and (b) spheres. Zr weight percentage after different number of cycles for (c) fabrics and (d) spheres, as determined by ICP-MS.

15 growth cycles shows the formation of a crystalline UiO-66 phase on the surface of $\mathrm{AC}$ materials after approximately three cycles. The MOF content in the materials increases with growth cycles. Similarly, Fourier transform infrared spectroscopy (FTIR) results (Figure S6) showed that vibrational bands associated with the bdc ligand (1100-1800 $\mathrm{cm}^{-1}$ region) increase with the increasing number of growth cycles. The amount of deposited $\mathrm{UiO}-66$ thin films, after nine cycles, was estimated to reach 0.422 and 0.496 wt \% MOF content for AC fabrics and spheres, respectively.

In a parallel study, we also addressed the UiO-66 typical solvothermal synthesis in the presence of shaped carbon materials. With this aim, the MOF precursors were mixed in a solvothermal reactor and heated at an elevated temperature $\left(220{ }^{\circ} \mathrm{C}\right)$ and pressure overnight. This process was repeated during nine growth cycles leading to the formation of microcrystalline $\mathrm{UiO}-66$ both attached to the shaped AC together with a large excess of loose MOF materials. Scanning electron microscopy (SEM) images show a heterogeneous distribution of UiO-66 microcrystals on the external surface of the AC spheres and fibers giving rise to terraces and granules (Figure 2a-c). The observed behavior for the solvothermalprepared UiO-66@AC composites is in clear contrast to a homogeneous film formation observed for the LBL-prepared composites (Figures $2 \mathrm{e}-\mathrm{h}$ and 3 ).

In a second stage in this work, we prepared a new set of MOF@AC composite materials of UiO-66 and UiO-66- $\mathrm{NH}_{2}$ networks, reducing the time length of each growth cycle from 2 $\mathrm{h}$ to $30 \mathrm{~min}$ over nine cycles. The results show the successful preparation of UiO-66@AC(fabrics, spheres) and UiO-66$\mathrm{NH}_{2} @ A C($ fabrics, spheres) composites. PXRD patterns (Figure 3a,g) show the presence of crystalline MOF over the
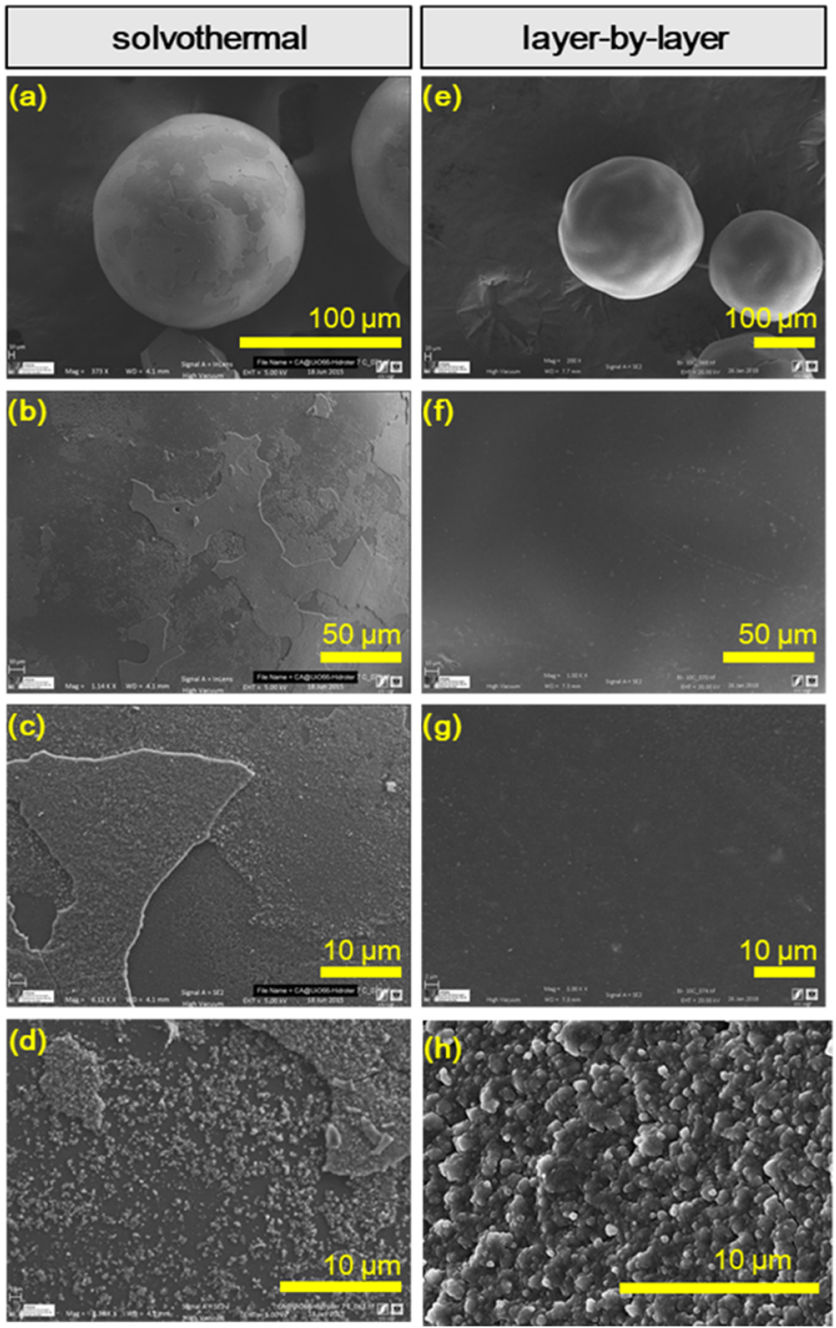

Figure 2. Comparison between solvothermal and LBL syntheses. SEM images at three different magnifications for $(a-d)$ solvothermally prepared and $(\mathrm{e}-\mathrm{h})$ LBL-prepared (cycle 10$)$ composites $(2 \mathrm{~h}$ cycles at $130{ }^{\circ} \mathrm{C}$ ). For comparison, Figure S9 shows SEM images for pristine fabrics and spheres.

surface of all composites. TGA analysis (Figures S7 and S8) shows an increased pyrolytic residue for the MOF@AC composite materials indicative of the presence of $\mathrm{ZrO}_{2}$ from the Zr-MOF layer. ICP analysis (Table 1) showed Zr wt \% values ranging from 0.022 to 0.051 corresponding to $0.07-$ $0.16 \%$ MOF incorporation on the MOF@AC composites (Table 1). SEM-EDX mapping analyses (Figures $3 \mathrm{c}-\mathrm{f}, \mathrm{i}-\mathrm{l}$ and S10) show a homogeneous dispersion of $\mathrm{Zr}$ and MOF crystals on the external surface of the activated carbon shaped bodies. A cross-sectional elemental analysis of the fabric fiber showed a $\mathrm{Zr}$ signal only on the outer surface of the fibers with a layer thickness of approximately $300 \mathrm{~nm}$ (Figure S10). This is indicative of the preferential formation of the MOF thin-film layer at the hydrophilic external surface (oxygen groups) of AC shaped bodies with no MOF formation onto the inner hydrophobic AC pore surface. Nitrogen adsorption isotherms indicated that both the MOF and $\mathrm{AC}$ porous structures are accessible in the MOF@AC composites (Figure 3b,h and Table 1). A drop in the adsorption capacity of the activated carbon material of $19 \%$ for AC fabric and $9 \%$ for AC spheres is noticed upon the oxidation treatment, which can be related to the partial degradation of materials. A further adsorption 

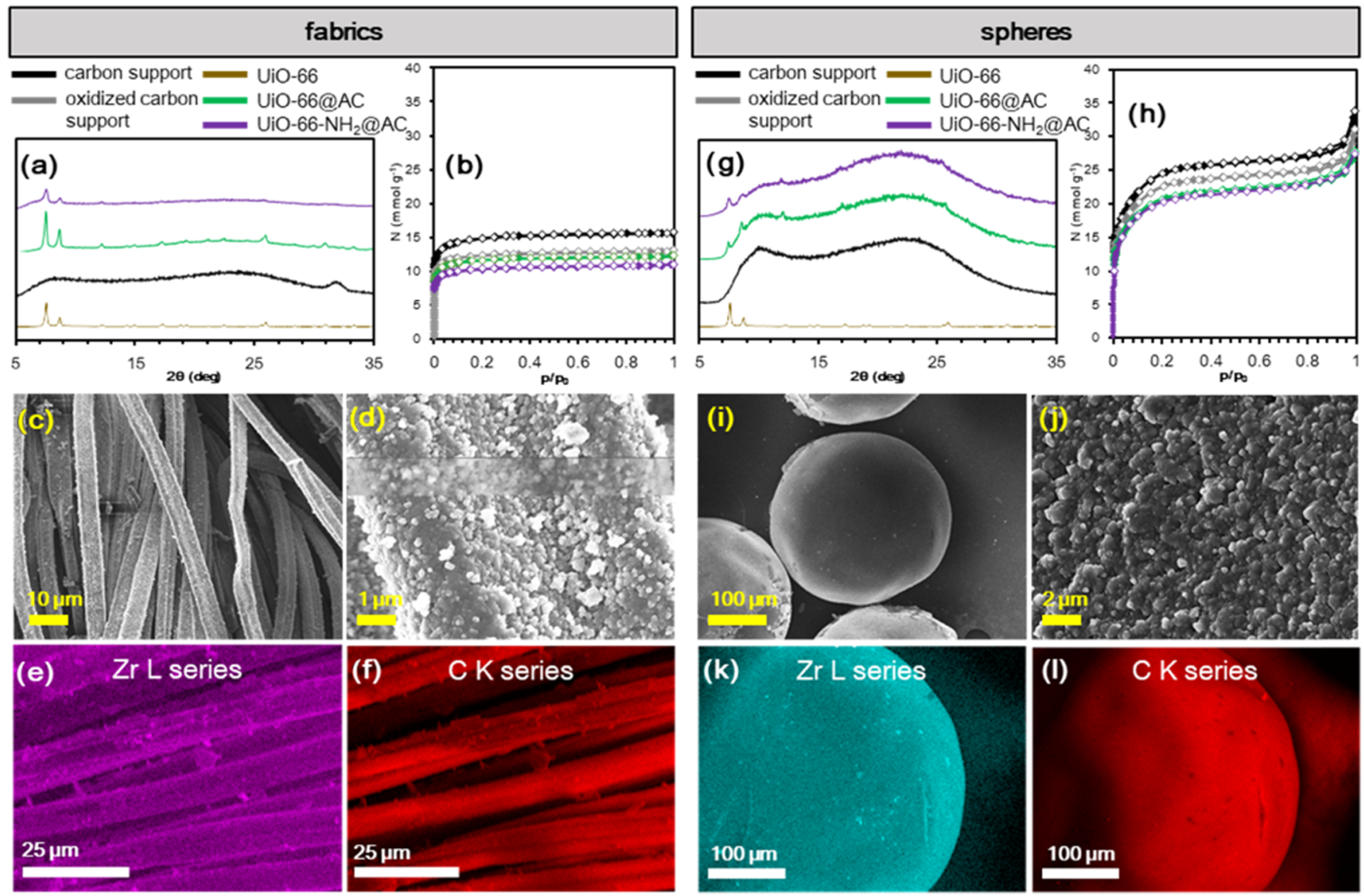

Figure 3. Characterization of Zr-MOF@AC composites (nine cycles, $130{ }^{\circ} \mathrm{C}, 30$ min each cycle). PXRD patterns for (a) fabrics and (g) spheres and nitrogen adsorption isotherms for (b) fabrics and (h) spheres. SEM-energy dispersive X-ray analysis (EDX) study of (c-f) UiO-66@ AC(fabrics) and (i-1) UiO-66@AC(spheres). Color code: pristine carbon (black), $\mathrm{H}_{2} \mathrm{O}_{2}$-mediated oxidized carbon (gray), UiO-66@CA (green), and UiO-66- $\mathrm{NH}_{2} @ \mathrm{CA}$ (purple).

Table 1. Textural and Compositional Characteristics of MOF@AC Materials

\begin{tabular}{|c|c|c|c|c|c|}
\hline material & $V_{\mathrm{p}}\left(\mathrm{cm}^{3} \mathrm{~g}^{-1}\right)$ & $S_{\text {BET }}\left(\mathrm{m}^{2} \mathrm{~g}^{-1}\right)$ & Zr wt \% & estimated MOF wt \% & estimated MOF in the catalyst (mg) \\
\hline carbon fabrics & 0.50 & 1070 & & & \\
\hline oxidized carbon fabrics & 0.42 & 1040 & & & \\
\hline UiO-66@AC(fabrics) & 0.40 & 840 & 0.051 & 0.16 & 0.06 \\
\hline UiO-66- $\mathrm{NH}_{2} @ \mathrm{AC}($ fabrics $)$ & 0.34 & 745 & 0.048 & 0.15 & 0.06 \\
\hline carbon spheres & 0.87 & 2045 & & & \\
\hline oxidized carbon spheres & 0.80 & 1880 & & & \\
\hline UiO-66@AC(spheres) & 0.73 & 1520 & 0.041 & 0.12 & \\
\hline UiO-66- $\mathrm{NH}_{2} @ \mathrm{AC}$ (spheres) & 0.72 & 1495 & 0.022 & 0.07 & \\
\hline
\end{tabular}

capacity drop is also noticed after the MOF layer deposition of around 5 and $15 \%$ for the fabric and spheres, respectively, which might be the related to hindered diffusion of $\mathrm{N}_{2}$ molecules through the microporous MOF layer and/or adsorbed organic linkers, thereby reducing their associated porosity. Slightly lower adsorption capacities for UiO-66$\mathrm{NH}_{2} @ \mathrm{AC}$ composites are attributed to the steric effects of the $\mathrm{NH}_{2}$ group.

Once we structurally characterized the MOF@AC composites, we proceeded to evaluate their possible functionality for detoxification of CWAs, as a proof of concept for self-cleaning materials. With this aim, we have evaluated the activity of UiO66(UiO-66- $\left.\mathrm{NH}_{2}\right) @ \mathrm{AC}($ fabrics) in the catalytic hydrolysis of the nerve agent simulant diisopropyl fluorophosphate (DIFP) (Figure 4a). For this reaction, $40 \mathrm{mg}$ of the MOF@AC catalyst was impregnated with $10 \mu \mathrm{L}$ of $\mathrm{H}_{2} \mathrm{O}$ and $1.25 \mu \mathrm{L}$ of DIFP
(MOF/DIFP ratio of approximately 1:5) in a closed vial. Subsequently, the vials were incubated at $60{ }^{\circ} \mathrm{C}$ for increasing time periods at $1,10 \mathrm{~min}, 1,5$, and $24 \mathrm{~h}$, followed by the extraction with $\mathrm{CH}_{2} \mathrm{Cl}_{2}(0.5 \mathrm{~mL})$ and analysis by GC. The results are indicative of self-cleaning behavior for UiO-66@ $\mathrm{AC}$ (fabric) and UiO-66- $\mathrm{NH}_{2} @ \mathrm{AC}$ (fabric) composites with respective 80 and 40\% DIFP detoxification after $24 \mathrm{~h}$ (Figures $4 \mathrm{c}$ and S7). Figure $4 \mathrm{~b}$ shows the plausible mechanism of the three-step model nerve agent detoxification process. In the first step, fast and strong adsorption of DIFP on the hydrophobic activated carbon pore structure takes place, accounting for the traditional protective behavior of activated carbon materials. In the second step, a slow equilibrium takes place between the physisorbed contaminant (secondary emission) and the MOF particles that are distributed over the external surface of the activated carbon fibers. Finally, DIFP is hydrolyzed on the Zr- 

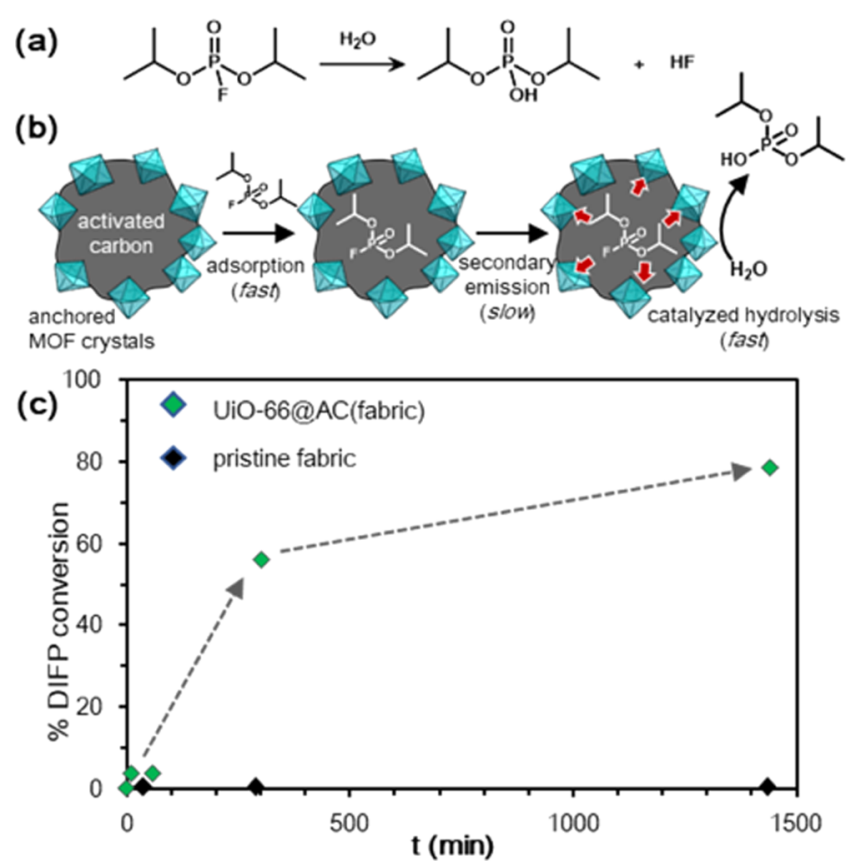

Figure 4. Blocking of the secondary emission by MOF@AC materials. (a) DIFP hydrolytic reaction. (b) Proposed three-step mechanism for the synergistic detoxification of DIFP on the composite surface. (c) DIFP hydrolysis kinetic study. Reaction conditions: $40 \mathrm{mg}$ of the MOF@AC catalyst, $1.25 \mu \mathrm{L}$ of DIFP, $10 \mu \mathrm{L}$ of $\mathrm{H}_{2} \mathrm{O}$, MOF/DIFP ratio of approximately $1: 5,60{ }^{\circ} \mathrm{C}$. Extraction with $\mathrm{CH}_{2} \mathrm{Cl}_{2}(0.5 \mathrm{~mL})$ at $1,10 \mathrm{~min}, 1,5$, and $24 \mathrm{~h}$.

MOF pore structure, as shown in previous works. ${ }^{23-25}$ The observed lower performance of UiO-66- $\mathrm{NH}_{2} @ \mathrm{AC}$ (fabric) might be related to a $\mathrm{pH}$ effect of unbuffered media as recently found by Cohen and co-workers. ${ }^{26} \mathrm{We}$ assume the secondary emission diffusion process as the rate-limiting step in this detoxification process. In this regard, DIFP secondary emission is only appreciable above room temperature, as demonstrated previously by our group for AC Blücher spheres. ${ }^{27}$ It should be noted that the pristine $\mathrm{AC}$ fabrics do not give rise to any DIFP degradation under similar conditions, which indicated the benefit of the incorporation of the MOF layer on the AC fabrics to yield self-cleaning adsorbent materials.

Nevertheless, a similar study on the UiO-66@AC(spheres) composites is indicative of no improvement in the detoxification properties upon incorporation of the MOF layer (Figure S13), which can be attributed to the strong competition of the adsorption process on the spheres pore structure with the detoxification properties on the UiO-66 layer. This result correlates with the much higher adsorption capacity and Brunauer-Emmett-Teller (BET) surface of AC spheres in comparison to AC fabrics.

\section{CONCLUSIONS}

The controlled layer-by-layer growth of crystalline MOF thin films over AC shaped substrates can be regarded as a suitable approach for the fabrication of advanced self-cleaning porous materials. The characterization results demonstrated the high dispersion of Zr-MOF crystals, and catalysis results showed their efficiency in the blocking of the secondary emission problem of classical CWA protective garments. We can conclude that the combination of two porous materials of different characteristics (porous hydrophobic carbon and catalytically active hydrophilic MOF) is a suitable way of improving the features of activated carbon traditional protective filters. Further work needs to be carried out to find a suitable balance between physisorption of CWA on a hydrophobic adsorbent and hydrolytic detoxification on a hydrophilic MOF to bring these composites to real applications.

\section{ASSOCIATED CONTENT}

sI Supporting Information

The Supporting Information is available free of charge at https://pubs.acs.org/doi/10.1021/acsami.1c12095.

Details of experimental procedures, composite preparation, and characterization (PDF)

\section{AUTHOR INFORMATION}

\section{Corresponding Author}

Jorge A. R. Navarro - Departamento de Química Inorgánica, Universidad de Granada, 18071 Granada, Spain; 이이.org/0000-0002-8359-0397; Email: jarn@ugr.es

\section{Authors}

Rodrigo Gil-San-Millan - Departamento de Química Inorgánica, Universidad de Granada, 18071 Granada, Spain; Present Address: Faculty of Chemistry, University of Wrocław, F. Joliot-Curie 14, 50-383 Wrocław, Poland; (1) orcid.org/0000-0003-2502-4781

Pedro Delgado - Departamento de Química Inorgánica, Universidad de Granada, 18071 Granada, Spain; (1) orcid.org/0000-0002-3948-9419

Elena Lopez-Maya - Departamento de Química Inorgánica, Universidad de Granada, 18071 Granada, Spain; Present Address: Chemistry Department \& CICECO, University of Aveiro, 3810-193 Aveiro, Portugal.; 이이.org/00000001-8173-0328

Javier D. Martin-Romera - Departamento de Química Inorgánica, Universidad de Granada, 18071 Granada, Spain

Elisa Barea - Departamento de Química Inorgánica, Universidad de Granada, 18071 Granada, Spain; - orcid.org/0000-0001-9895-1047

Complete contact information is available at:

https://pubs.acs.org/10.1021/acsami.1c12095

\section{Author Contributions}

R.G.-S.-M. and P.D. contributed equally to this work. The manuscript was written through contributions of all authors. All authors have given approval to the final version of the manuscript.

\section{Funding}

This research was funded by the Directorate for Planning, Technology, and Innovation (SDG PLATIN) from the Directorate General of Armaments and Material (DGAM) of the Spanish Ministry of Defense, COINCIDENTE Program exp. 1003219007500-NBQD2. The authors also acknowledge EU Feder funding, MINECO (CTQ2017-84692-R and PID2020-113608RB-I00), Universidad de Granada (Plan Propio de Investigación), and Junta de Andalucia (P18-RT612). Funding for open access charge: Universidad de Granada/CBUA.

\section{Notes}

The authors declare no competing financial interest. 


\section{REFERENCES}

(1) Giannakoudakis, D. A.; Bandosz, T. J. Detoxification of Chemical Warfare Agents: From WWI to Multifunctional Nanocomposite Approaches; Springer International Publishing, 2018.

(2) Mercey, G.; Verdelet, T.; Renou, J.; Kliachyna, M.; Baati, R.; Nachon, F.; Jean, L.; Renard, P.-Y. Reactivators of Acetylcholinesterase Inhibited by Organophosphorus Nerve Agents. Acc. Chem. Res. 2012, 45, 756-766.

(3) Chauhan, S.; Chauhan, S.; D'Cruz, R.; Faruqi, S.; Singh, K. K.; Varma, S.; Singh, M.; Karthik, V. Chemical Warfare Agents. Environ. Toxicol. Pharmacol. 2008, 26, 113-122.

(4) DeCoste, J. B.; Peterson, G. W. Metal-Organic Frameworks for Air Purification of Toxic Chemicals. Chem. Rev. 2014, 114, 56955727.

(5) Giannakoudakis, D. A.; Barczak, M.; Florent, M.; Bandosz, T. J. Analysis of Interactions of Mustard Gas Surrogate Vapors with Porous Carbon Textiles. Chem. Eng. J. 2019, 362, 758-766.

(6) Furukawa, H.; Cordova, K. E.; O’Keeffe, M.; Yaghi, O. M. The Chemistry and Applications of Metal-Organic Frameworks. Science 2013, 341, No. 1230444.

(7) Mondloch, J. E.; Katz, M. J.; Isley Iii, W. C.; Ghosh, P.; Liao, P.; Bury, W.; Wagner, G. W.; Hall, M. G.; DeCoste, J. B.; Peterson, G. W.; Snurr, R. Q.; Cramer, C. J.; Hupp, J. T.; Farha, O. K. Destruction of Chemical Warfare Agents Using Metal-Organic Frameworks. Nat. Mater. 2015, 14, 512-516.

(8) Bobbitt, N. S.; Mendonca, M. L.; Howarth, A. J.; Islamoglu, T.; Hupp, J. T.; Farha, O. K.; Snurr, R. Q. Metal-Organic Frameworks for the Removal of Toxic Industrial Chemicals and Chemical Warfare Agents. Chem. Soc. Rev. 2017, 46, 3357-3385.

(9) Jabbour, C. R.; Parker, L. A.; Hutter, E. M.; Weckhuysen, B. M. Chemical Targets to Deactivate Biological and Chemical Toxins Using Surfaces and Fabrics. Nat. Rev. Chem. 2021, 5, 370-387.

(10) Castells-Gil, J.; M Padial, N.; Almora-Barrios, N.; Gil-SanMillán, R.; Romero-Ángel, M.; Torres, V.; da Silva, I.; Vieira, B. C. J.; Waerenborgh, J. C.; Jagiello, J.; Navarro, J. A. R.; Tatay, S.; MartíGastaldo, C. Heterometallic Titanium-Organic Frameworks as DualMetal Catalysts for Synergistic Non-Buffered Hydrolysis of Nerve Agent Simulants. Chem 2020, 6, 3118-3131.

(11) Tian, T.; Zeng, Z.; Vulpe, D.; Casco, M. E.; Divitini, G.; Midgley, P. A.; Silvestre-Albero, J.; Tan, J.-C.; Moghadam, P. Z.; Fairen-Jimenez, D. A Sol-Gel Monolithic Metal-Organic Framework with Enhanced Methane Uptake. Nat. Mater. 2018, 17, 174-179.

(12) López-Maya, E.; Montoro, C.; Rodríguez-Albelo, L. M.; Aznar Cervantes, S. D.; Lozano-Pérez, A. A.; Cenís, J. L.; Barea, E.; Navarro, J. A. R. Textile/Metal-Organic-Framework Composites as SelfDetoxifying Filters for Chemical-Warfare Agents. Angew. Chem. Int. Ed. 2015, 54, 6790-6794.

(13) Lu, A. X.; McEntee, M.; Browe, M. A.; Hall, M. G.; DeCoste, J. B.; Peterson, G. W. MOFabric: Electrospun Nanofiber Mats from PVDF/UiO-66-NH2 for Chemical Protection and Decontamination. ACS Appl. Mater. Interfaces 2017, 9, 13632-13636.

(14) Chen, Z.; Ma, K.; Mahle, J. J.; Wang, H.; Syed, Z. H.; Atilgan, A.; Chen, Y.; Xin, J. H.; Islamoglu, T.; Peterson, G. W.; Farha, O. K. Integration of Metal-Organic Frameworks on Protective Layers for Destruction of Nerve Agents under Relevant Conditions. J. Am. Chem. Soc. 2019, 141, 20016-20021.

(15) Lee, D. T.; Jamir, J. D.; Peterson, G. W.; Parsons, G. N. Protective Fabrics: Metal-Organic Framework Textiles for Rapid Photocatalytic Sulfur Mustard Simulant Detoxification. Matter 2020, 2, 404-415.

(16) Lee, D. T.; Zhao, J.; Peterson, G. W.; Parsons, G. N. Catalytic "MOF-Cloth" Formed via Directed Supramolecular Assembly of UiO66-NH2 Crystals on Atomic Layer Deposition-Coated Textiles for Rapid Degradation of Chemical Warfare Agent Simulants. Chem. Mater. 2017, 29, 4894-4903.

(17) Phadatare, A.; Kandasubramanian, B. Metal Organic Framework Functionalized Fabrics for Detoxification of Chemical Warfare Agents. Ind. Eng. Chem. Res. 2020, 59, 569-586.
(18) Soleimanpour, A.; Farsi, M.; Keshavarz, P.; Zeinali, S Modification of Activated Carbon by MIL-53(Al) MOF to Develop a Composite Framework Adsorbent for $\mathrm{CO} 2$ Capturing. Environ. Sci. Pollut. Res. 2021, 28, 37929-37939.

(19) Muñoz-Senmache, J. C.; Kim, S.; Arrieta-Pérez, R. R.; Park, C. M.; Yoon, Y.; Hernández-Maldonado, A. J. Activated Carbon-Metal Organic Framework Composite for the Adsorption of Contaminants of Emerging Concern from Water. ACS Appl. Nano Mater. 2020, 3, 2928-2940.

(20) McHugh, L. N.; Terracina, A.; Wheatley, P. S.; Buscarino, G.; Smith, M. W.; Morris, R. E. Metal-Organic Framework-Activated Carbon Composite Materials for the Removal of Ammonia from Contaminated Airstreams. Angew. Chem., Int. Ed. 2019, 58, 1174711751.

(21) de Oliveira, C. A. F.; da Silva, F. F.; Jimenez, G. C.; Neto, J. F. D. S.; de Souza, D. M. B.; de Souza, I. A.; Júnior, S. A. MOF@ activated Carbon: A New Material for Adsorption of Aldicarb in Biological Systems. Chem. Commun. 2013, 49, 6486-6488.

(22) DeStefano, M. R.; Islamoglu, T.; Garibay, S. J.; Hupp, J. T.; Farha, O. K. Room-Temperature Synthesis of UiO-66 and Thermal Modulation of Densities of Defect Sites. Chem. Mater. 2017, 29, $1357-1361$.

(23) Gil-San-Millan, R.; López-Maya, E.; Hall, M.; Padial, N. M.; Peterson, G. W.; DeCoste, J. B.; Rodríguez-Albelo, L. M.; Oltra, J. E.; Barea, E.; Navarro, J. A. R. Chemical Warfare Agents Detoxification Properties of Zirconium Metal-Organic Frameworks by Synergistic Incorporation of Nucleophilic and Basic Sites. ACS Appl. Mater. Interfaces 2017, 9, 23967-23973.

(24) Gil-San-Millan, R.; López-Maya, E.; Platero-Prats, A. E.; Torres-Pérez, V.; Delgado, P.; Augustyniak, A. W.; Kim, M. K.; Lee, H. W.; Ryu, S. G.; Navarro, J. A. R. Magnesium Exchanged Zirconium Metal-Organic Frameworks with Improved Detoxification Properties of Nerve Agents. J. Am. Chem. Soc. 2019, 141, 11801-11805.

(25) Moon, S.-Y.; Wagner, G. W.; Mondloch, J. E.; Peterson, G. W.; DeCoste, J. B.; Hupp, J. T.; Farha, O. K. Effective, Facile, and Selective Hydrolysis of the Chemical Warfare Agent VX Using Zr6Based Metal-Organic Frameworks. Inorg. Chem. 2015, 54, 1082910833.

(26) Palomba, J. M.; Credille, C. V.; Kalaj, M.; De Coste, J. B.; Peterson, G. W.; Tovar, T. M.; Cohen, S. M. High-throughput screening of solid-state catalysts for nerve agent degradation. Chem. Commun. 2018, 54, 5768-5771.

(27) Montoro, C.; Linares, F.; Quartapelle Procopio, E.; Senkovska, I.; Kaskel, S.; Galli, S.; Masciocchi, N.; Barea, E.; Navarro, J. A. R. Capture of Nerve Agents and Mustard Gas Analogues by Hydrophobic Robust MOF-5 Type Metal-Organic Frameworks. J. Am. Chem. Soc. 2011, 133, 11888-11891. 